\title{
Conceptual Truths, Strong Possibilities and Our Knowledge of Metaphysical Necessities
}

\section{Christian Nimtz}

\section{(2) OpenEdition \\ 1 Journals}

\section{Electronic version}

URL: http://journals.openedition.org/philosophiascientiae/735

DOI: 10.4000/philosophiascientiae.735

ISSN: $1775-4283$

\section{Publisher}

Éditions Kimé

\section{Printed version}

Date of publication: 1 October 2012

Number of pages: $39-58$

ISBN: 978-2-84174-592-0

ISSN: 1281-2463

\section{Electronic reference}

Christian Nimtz, «Conceptual Truths, Strong Possibilities and Our Knowledge of Metaphysical Necessities », Philosophia Scientiæ [Online], 16-2 | 2012, Online since 01 October 2015, connection on 02 November 2020. URL : http://journals.openedition.org/philosophiascientiae/735 ; DOI : https:// doi.org/10.4000/philosophiascientiae.735 


\title{
Conceptual Truths, Strong Possibilities and Our Knowledge of Metaphysical Necessities
}

\author{
Christian Nimtz \\ Bielefeld University (Germany)
}

Résumé : Dans mon article, je soutiens qu'il existe une voie épistémique fiable qui mène de la connaissance des vérités conceptuelles à celle des nécessités métaphysiques. Dans un premier temps, je montre que nous pouvons prétendre connaitre des vérités conceptuelles dans la mesure où nous savons à quelles conditions nos termes (ou du moins un grand nombre d'entre eux) s'appliquent. Je défends notamment cette idée face à un argument récent que Williamson adresse à la conception épistémique de l'analyticité. Dans un second temps, je montre que notre connaissance des vérités conceptuelles constitue un moyen fiable de connaître des nécessités métaphysiques. En effet, de deux choses l'une : ou bien la connaissance conceptuelle conduit directement à la connaissance de nécessités métaphysiques; ou bien, lorsque ce n'est pas le cas, nous pouvons du moins savoir qu'une telle inférence n'est pas permise, en vertu d'une réflexion purement sémantique, «depuis notre fauteuil » (armchair). J'en conclus que la connaissance conceptuelle constitue un moyen sûr d'acquérir des connaissances modales.

Abstract: I argue that there is a reliable epistemic route from knowledge of conceptual truths to knowledge of metaphysical necessities. In a first step, I argue that we possess knowledge of conceptual truths since we know what (many of) our terms apply to. I bolster this line of thought with a rebuttal of Williamson's recent argument against epistemic analyticity. In a second step, I argue that our knowledge of conceptual truths allows us to reliably attain knowledge of metaphysical necessities. Either this knowledge straightforwardly yields knowledge of metaphysical necessities. Or it is such that we can by armchair semantic reflection discover that it fails to do so. I conclude that conceptual knowledge provides a safe route to modal knowledge.

Philosophia Scientiæ, 16 (2), 2012, 39-58. 


\section{The simple argument introduced}

The category of metaphysically necessary statements ${ }^{1}$ —of metaphysical necessities, for short-is widely held to be of particular importance to philosophical inquiry. Following Kripke [Kripke 1980, 34-60], everyone agrees that metaphysical necessity contrasts with the traditional categories of logical, conceptual and nomological necessity in that there are metaphysical necessities that cannot be discovered by a priori reflection, in that there are metaphysical necessities that aren't analytic, and in that metaphysical necessities hold true in all possible worlds simpliciter. Beyond this, there is no consensus on what makes a necessity a metaphysical necessity, or what marks off metaphysical modality in general [Cameron 2009].

Metaphysical necessity poses two interlocked puzzles. On the one hand, there is the metaphysical puzzle of what, if anything, grounds metaphysical modality [Cameron 2010], [Hale \& Hoffmann 2010, part I]. On the other hand, there is the epistemic puzzle of how we may arrive at knowledge of metaphysical necessities [Vaidya 2007], [Roca-Royes 2011], [McLeod 2005], [Hale \& Hoffmann 2010, part II]. I will be dealing with the epistemic puzzle. I argue that our ordinary knowledge of conceptual truths, knowledge we possess since we know what (many of) our terms semantically apply to, ${ }^{2}$ is a reliable epistemic source of, and hence a reliable route to, knowledge of metaphysical necessities. (I will often shorten 'knowledge of conceptual truths' to 'conceptual knowledge', and unless indicated otherwise, I will take 'modal knowledge' to mean 'metaphysically modal knowledge'.) Here is the argument I put forth. I call it the simple argument for modal knowledge, or just the simple argument:

(1) We possess conceptual knowledge, since we know for (many of) our terms what they semantically apply to.

(2) Any item of conceptual knowledge we so possess either ipso facto is knowledge of a metaphysical necessity. Or the conceptual knowledge we are concerned with is such that we can reliably determine that it does not lead to modal knowledge.

Hence:

(3) The conceptual knowledge we possess since we know what (many of) our terms apply to reliably yields knowledge of metaphysical necessities.

That conceptual knowledge yields modal knowledge has been argued before, notably by Peacocke and Bealer. So let me accentuate what is distinctive about the simple argument.

1. As I employ the term, a 'statement' is an interpreted sentence.

2. The "semantically" in "semantically applies" is of course redundant. For to say of a term ' $F$ ' that it applies to something just is to mark off one of its semantic properties. I put the 'semantically' in for emphasis. 
Peacocke and Bealer both draw on bold background designs. In his actualist metaphysics of modality, Peacocke postulates implicitly known general principles that at the same time govern modality, and give rise to modal knowledge [Peacocke 1999], [Peacocke 2002]. This scheme has proved controversial both in technical detail [Williamson 2002] and in principle [Rosen 2002]. Bealer enlists an understanding of concepts as sparse ante rem universals with characteristic possession conditions [Bealer 2000, esp. 21ff], [Peacocke 1999, 299f], [Sosa 1998]. On his view, a thinker $A$ determinately possesses some concept $C$ only if, simply put, $A s$ rational intuitions track the true nature of the property of being $C$. Determinate concept possession thereby virtually ensures modal knowledge, but it turns out to be exceedingly demanding. On these standards, few humans (if any) will ever determinately possess a concept. That is why Bealer [Bealer 2000, 12, 23f] merely argues that determinate concept possession is metaphysically possible.

The simple argument contrasts sharply with either approach. It rests neither on an ambitious metaphysics of modality, nor on an extravagant theory of concept possession. The argument is designed to be, well, simple. It aims to establish a connection between knowledge of conceptual truths and knowledge of metaphysical necessities drawing on widely shared views of our knowledge of our terms' semantic properties, and on ideas about modality that are deeply entrenched in the standard view of modal space.

Here is what I will do. I begin by arguing that, since we know how we do and would apply our terms (§2) and since, as neo-descriptivists and orthodox Kripkeans agree, considered application often determines semantic properties, we often know what our terms semantically apply to, and thereby possess conceptual knowledge (§3). I go on to defuse Williamson's recent charge that there is no conceptual knowledge, since there are no epistemic analyticities (§ 4). Drawing on common ideas about modal space, I then argue that all defeaters to the universal rule that knowledge of conceptual truths is ipso facto knowledge of metaphysical necessities are, as it were, harmless. I conclude that the conceptual knowledge we possess since we know what (many of) our terms apply to does indeed give rise to modal knowledge ( $§ 5$ ). I close by reviewing my argument, and by wondering whether there is anything left to do in modal epistemology (§6).

\section{From considered application to knowledge of notions}

The simple argument rests on the epistemological premise that:

(1) We possess conceptual knowledge, since we know for (many of) our terms what they apply to. 
This premise combines two claims: (i) we do have knowledge of conceptual truths, and (ii) we do have knowledge of conceptual truth since we know for (many of) our terms what they apply to. Either claim may appear contentious. Yet if we start from mundane facts about how we use language and work our way up to standard semantic theories, we find that there should be sufficient common ground to support both. ${ }^{3}$

Here is a patent truth about the way we use language: To which entities we do and would apply our (classificatory) terms depends on the properties we take those entities to have. For example, I call a liquid 'flammable' because I take it to ignite easily, I call John a 'liar' because I take him to have intentionally presented a falsehood as truth, and I call Venus a 'planet' because I take it that it meets the criteria laid down by the IAU. These characterizations aptly reveal what properties the considered application of my terms is sensitive to. After all, they all sustain the pertinent counterfactuals. It is not just that I do call a liquid 'flammable' if I take it to ignite easily. I also would call a liquid 'flammable' if I were to take it to ignite easily.

In order to coin some terminology apt to generalize these observations, let the notion a speaker associates with some term ' $F$ ' ${ }^{4}$ be the conditions something has to satisfy such that the speaker does and would, on reflection, apply ' $F$ ' to it. The notion someone associates with a term ' $F$ ' guides her application of that term. That is simply to say that she does and would apply ' $F$ ' to something if she takes it to satisfy that notion. As revealed above, the notion I associate with 'flammable' is being such that it ignites easily, as this is what guides my considered application of the term. Please note that, as introduced, the notion of a 'notion' belongs to the theory of language use. Whether it is of relevance to semantics depends on the relevance of language use to semantics. (I will come back to this in the next section.)

The observations about language use rehearsed above sustain two general claims about notions. First, UBIQUITY: We quite generally associate notions with our terms guiding how we do and would reflectively apply them. The reason for this is plain to see. Our considered application of (classificatory) terms depends on the properties we take those entities to have. But notions just are the very properties our considered application is sensitive to. Hence, we quite generally associate notions with our terms guiding our considered application.

Secondly, ACCESS: We have readily available, yet presumably mostly tacit, non-trivial knowledge of what the notions we associate with our terms are. I call something a 'planet' because I take it to satisfy the notion I associate with 'planet'. That of course requires me to have readily available non-trivial knowledge of what this associated notion is, otherwise my considered application

3. For the following, see also [Nimtz 2010, 200ff]. With less emphasis on language use, Jackson [Jackson 2007a], [Jackson 2010] presents a similar line.

4. I throughout employ quotation marks in lieu of Quine-quotes. 
could not be sensitive to the conditions the notion encapsulates. Such an association will quite generally be forged by beliefs and/or dispositions on the part of the subject, and there is no guarantee that the readily available knowledge this yields will be explicit rather than tacit.

Still, we have no reason to think that our explicit armchair judgments on what we do and would apply our terms to are customarily unreliable. On the contrary, we quite generally find that our considered use is basically what we consider it to be. It hence is hardly surprising that (almost) everyone in philosophy treats speakers' answers to questions such as "Would you call an easily ignitable liquid 'flammable'?" or "Would you call a woollen bonnet a 'hat'?" as revealing their considered use-given that we allow them to reflect on the question, that we describe or present the relevant items with sufficient care, and that we present contrasting cases. Think of Kripke [Kripke 1980, 82ff] and Putnam [Putnam 1975, 223-227] on the one hand. Think of experimental philosophers on the other hand [Knobe \& Nichols 2008]. For all their disagreement, they agree that subjects can reliably tell how they do and would apply their terms in specific possible cases.

Our armchair reflection on how we do and would apply our terms is arguably fit to reliably provide partial accounts of the notions we associate with our terms, or so everyone agrees. This consensus carries no assurance that coming up with a comprehensive account of any of our notions will be a simple affair. On the contrary, we typically need to generalize from the considered judgments we find ourselves making with respect to a limited assortment of possible cases. By consequence, our armchair-based accounts of the notions guiding our considered application are typically conjectural, always defeasible, and very often provisional. But we can apparently rest assured that providing explicit, if partial, accounts of the notions guiding the application of terms such as 'knowledge', 'circle', 'neighbour', 'poisonous', 'uncle', 'I' or 'flammable' is typically not beyond our epistemic ken.

\section{From knowledge of notions to conceptual knowledge}

I have argued that we associate notions with our terms guiding our considered application, and that we can (at least often and partially) determine what these notions are. These are claims about language use. Thus far, I have made no claims about semantic properties. So let us turn from use to semantics and ask: Do the notions guiding our considered application affect or constrain the semantic properties our terms have? Proponents of traditional descriptivism emphatically think they do [Ayer 1946, chap. 1-3], [Hanfling 2000]. Embracing 
the slogan that use determines meaning, ${ }^{5}$ traditional descriptivists hold that the notion we associate with any of our terms straightaway determines what this term semantically applies to. On this picture, 'flammable' or 'gold' as used by us apply to items that ignite easily and to yellowish metal substances, respectively, because these fit the notions we associate with these terms. The analogous holds true for proper names such as 'Nixon', and indexicals such as 'I' or 'here'. ${ }^{6}$

There is almost universal agreement that the traditional descriptive paradigm is flawed. What is controversial is whether it is beyond repair. Orthodox Kripkeans forcefully maintain that it is [Kripke 1980, 82-87, 118, 124], [Putnam 1975], [Soames 2002]. They point out that proper names such as 'Nixon' and natural kind terms such as 'water' designate rigidly and that Nixon and water thus could very well not have had the very properties we actually identify them by, that we habitually defer in our application of kind and artefact terms to experts in line with Putnam's [Putnam 1975, 227f] famed 'linguistic division of labour', and that our associated notions quite often contain factual falsehoods such that, strictly speaking, nothing satisfies them. From this they conclude that traditional descriptivism is fundamentally mistaken: The notions we associate with names and natural kind terms are extraneous to their semantics, or so orthodox Kripkeans maintain. What these terms do and would apply to is rather determined by the very items or samples we find at the beginning of the causal-historical chains our use of these terms belongs to [Kripke 1980, 9197]. For example, our term 'gold' applies to something $o$ in some possible world $w$ iff (i) the actual causal-historical chain our use of 'gold' belongs to originated with some sample $k$-maybe the producers of that term just ruled: "That (嚓) is gold", pointing to $k$-and (ii) $o$ is of the same natural kind as $k$.

Neo-descriptivists reject the causal-historical picture just sketched [Jackson 2010], [Jackson 2010, chap. 2], [Jackson 1998, chap. 2], [Lewis 1994], [Chalmers 2004], [Nimtz 2010]. They think that a semantics loyal to the descriptivist idea that our notions essentially fix the semantic properties of our expressions can account for factual errors, deference, and rigid designation. Factual errors are permitted since what a term applies to is fixed by best rather than by perfect fit with the associated notion [Lewis 1997, 358f], [Lewis 1972, 253], [Lewis 1994, 298]. Deference is accounted for by allowing individual notions to comprise explicitly deferential conditions along the lines of gold is the goldish stuff of our acquaintance our experts accept as gold [Jackson 2004, 270-273]. Finally, rigid designation and the counterfactual variation in surface properties that comes with it is accounted for by combining the idea that a term's application in a possible world is determined by a trans-world relation of

5. Here is a way to render precise what this slogan amounts to in our context: To hold that use determines meanings is to hold that the reference-determining semantic values of our terms (see [Lewis 1986, 27-55]) supervene on considered application alone.

6. Note that the idea that all terms are definable drawing on a limited stock of somehow basic terms is not part of the descriptivists' position. In fact, traditional descriptivists such as Ayer [Ayer 1946, chap. 3] or Hanfling [Hanfling 2000] clearly reject this idea. 
sameness-of-natural-kind to an actual sample-vide clause (ii) of the Kripkean proposal above-with the claim that this actual sample is determined by our associated notion rather than by historic origin. On neo-descriptivist premises, our term 'gold' applies to something $o$ in some possible world $w$ iff (i) there is a sample $k$ in the actual world such that $k$ best fits the notion we associate with 'gold', and (ii) $o$ is of the same natural kind as $k$.

Neo-decriptivists discern two perspectives we can take on possible worlds [Jackson 1998, 47-51]. We can consider a possible world $w$ as counterfactual. To do so, "one acknowledges that the actual world is fixed, and thinks of a possibility as a way the world might have been but is not" [Chalmers 2004, 159]-i.e., as a possible variation in how things are given that the actual world is how it is. Let me call a world considered thus a counterfactual or C-world (in symbols: $\square_{C} S$ ). These worlds capture the metaphysical dimension in modality in that a statement $S$ is metaphysically necessary iff $S$ is true in all C-worlds. Or we can consider a possible world as a possible variation in how things actually are, as "representing a way the actual world might turn out to be" [Chalmers 2004, 159]. Let me call a world considered thus a counter-actual or A-world. Counter-actual worlds are centred, i.e., they have at least a place, a time, and a speaker/thinker highlighted. Taking conceptual truth and conceptual necessity to be the very same thing, A-worlds afford a straightforward way to explain what conceptual truth comes to: A statement $S$ is conceptually necessary iff $S$ holds true in all A-worlds (in symbols: $\square_{A} S$ ).

Drawing on this modal distinction, neo-descriptivists can provide a quite precise account of how associated notions affect semantic properties, thereby making good on their idea that our notions are what essentially fixes what our terms apply to. Our notions straightforwardly determine what our terms apply to across all counter-actual worlds; a fortiori, they straightforwardly determine the actual extensions our terms have. However things turn out to be, 'flammable' applies to what best fits my notion being such that it ignites easily, and 'gold' applies to what best fits my notion being the goldish stuff of our acquaintance our experts accept as gold. Yet what terms such as 'gold' apply to in some counterfactual worlds might well not be what best satisfies the associated notion within that world. As explained above, a term's application across counterfactual worlds will often be determined by what is of the same natural kind as the items or samples the term actually applies to. Of course, this actual extension is always straightforwardly fixed by the associated notion.

The pronounced differences in the semantic theories proffered by orthodox Kripkeans and neo-descriptivists ${ }^{7}$ should not blind us to their substantial agreement. Their dispute concerns specific kinds of expressions, notably proper names such as 'Nixon' and natural kind terms such as 'gold' or 'tiger'-terms whose semantic properties are, according to the typical orthodox Kripkean, fixed causalhistorically. Yet both parties agree that our language comprises quite a lot of

7. See e.g., [Spicer 2010] for a Kripkean rebuttal of neo-descriptivist ideas. 
expressions that, modulo deference, fit the traditional decriptivists' paradigm. Expressions such as 'circle', 'neighbour', 'poisonous', 'uncle' or 'flammable' are cases in point. These do not designate rigidly, and the orthodox Kripkean wouldn't think that their application is determined causal-historically-no orthodox Kripkean is an externalist about 'uncle'. Orthodox Kripkeans and neodescriptivists also agree that terms such as 'I' or 'the actual winner of the Man Booker Prize 2005' fit the neo-descriptivists account in that they designate rigidly whatever satisfies the associated descriptive condition, a condition that is encapsulated in the notion guiding our considered application of these terms. In the end, then, orthodox Kripkean and neo-descriptivists agree that semantic properties are often determined by associated notions, yet quarrel over the range of expressions actually fitting this model. Given that we can (at least often and partially) determine what the notion we associate with a term is, we hence find that Kripkeans and neo-descriptivists agree that we (at least often and partially) know what our terms apply to.

So what we find is that (i) our considered application of our terms is guided by the notions we associate with these expressions across the board, that (ii) armchair reflection on how we do and would apply our terms is arguably fit to reliably provide partial accounts of the notions we associate with our terms, and that (iii) there is a broad consensus that, at least in many cases, our associated notions determine the semantic properties of our terms. More precisely, if the orthodox Kripkean is right, notions determine what our terms semantically apply to in many, yet by no means in all cases, whereas if the neo-descriptivists' analysis holds true, notions determine at least application across counter-actual worlds across the board. But given that we know what our terms apply to, we ipso facto are in a position to have knowledge of conceptual truths. Since I know that 'uncle' applies to male relatives, and that 'circle' applies to geometric figures, I know that uncles are male relatives, and that circles are geometric figures.

I conclude that we have every reason to believe that we do possess knowledge of conceptual truths, and that we do so since we know for (at least many of) our terms what they semantically apply to. This fits nicely with our pretheoretical convictions. It seems very hard to deny that my knowledge of what my terms apply to puts me in a position to accurately judge that, say, "You do not know that $p$ if $p$ is false", "Neighbours have neighbours", "Uncles are relatives" or "Hats are coverings of the head" hold true. In fact, any doubt on this matter has a decidedly skeptical feel to it.

\section{Against Williamson against epistemic analyticity}

Acknowledging conceptual knowledge commits us to acknowledge analytic truths. At minimum, acknowledging conceptual knowledge requires us to ac- 
knowledge epistemically analytic truths held to be "such that one can determine their truth-value merely by grasping the meanings of the terms that occur in them" [Grayling 1997, 33], cf. also [Boghossian 1997, 334], [Boghossian 2003]. However, Williamson has recently argued that "no truths are analytic in the epistemological sense" [Williamson 2006, 8]. ${ }^{8}$ So before we can rest assured that we do in fact have conceptual knowledge, I need to review Williamson's case. ${ }^{9}$

Williamson argues that "[f]or even the simplest candidates for analyticity or conceptual truth, understanding is consistent with considered rejection" [Williamson 2006, 32]. Consider Peter, an expert logician who holds the odd view that universal quantification in English is existentially committing in that: "There is at least one $F$ " is a necessary condition for the truth of "Every $F$ is $G$ ". ${ }^{10}$ Peter has also been swayed by a curious conspiracy theory to believe that there are no vixens. Since he holds that the existential commitment of "Every vixen is a vixen" is not fulfilled, Peter neither assents to "Every vixen is a vixen", nor believes the thought it expresses.

According to Williamson, Peter nevertheless understands this sentence and grasps the thought it expresses. Peter understands 'vixen' just as we do, taking it to be synonymous to 'female fox'. He also understands the mode of combination used in "Every vixen is a vixen". More importantly still, Peter understands the English 'every' occurring in "Every vixen is a vixen". He is a native English speaker with a standard learning history whose conception makes little difference in practice-since Peter classifies what we consider a pragmatic presupposition as a logical inference, we usually do not even notice his deviation. Peter is also not trying to reform our language. He intends his theory to capture the meaning of 'every' in English, and he agrees to revise his account if he is proven wrong on this. What is peculiar about Peter thus is his logical theory, not his understanding, and as Williamson stresses:

Giving an incorrect theory of the meaning of a word is not the same as using the word with an idiosyncratic sense. [Williamson 2006, 12]

Williamson concludes that neither "Every vixen is a vixen", nor "Every vixen is a female fox" is epistemically analytic. He maintains that this line of thought smoothly generalizes. Since we can find some 'logical unorthodoxy' [Williamson 2006, 32] in any single case, there simply are no epistemic analyticities.

By way of reply, note first that Peter is acutely aware of how he uses 'every', as well as of the fact that his use differs from ours. In fact, Williamson stipulates that Peter's "refusal to accept ['Every vixen is a vixen'] as true is stable under conscious reflection, exposure to further arguments and the like" [Williamson

8. Williamson presents the very same case in very much the same words in chapter 4 of his [Williamson 2007]. I stick to the original paper.

9. For a more elaborate development of the case presented here, see [Nimtz 2009]. See also [Balcerak Jackson 2009] for objections to Williamson's line of thought.

10. I focus throughout on one of Williamson's two examples. 
$2006,16]$. Hence, in clear contrast to the way we use 'every', Peter reflectively employs the terms such that his "Every $F$ is $G$ " entails "There is at least one $F$ ". The deliberate and reflected use Peter makes of 'every' accords, moreover, with his theory. We thus find that the use Peter makes of 'every' fits his own theory, but systematically deviates from how we use that term.

This marked difference in considered and theory-guided use gives us every reason to conclude that Peter's "Every $F$ is $G$ " differ in truth-conditions of our "Every $F$ is $G$ ". Since everyone agrees that a difference in truth-conditions makes for a difference in thought expressed, we find that 'every' in Peter's mouth does differ in sense from 'every' in our mouths. Pace Williamson, Peter thus attaches an idiosyncratic sense to 'every', and he does so precisely because his theory accords with him using it in an idiosyncratic fashion. Williamson rightly points out that holding an incorrect theory of a word's meaning is not the same as using the word in an idiosyncratic sense. But he does not appreciate the fact that the former can be a sure sign of the latter if the incorrect theory conforms to, or even shapes the speaker's reflected use. This is precisely what we find in Peter's case. I therefore conclude that Peter does not grasp the thought we express with "Every vixen is a vixen". Hence, we have no reason to believe that not even this simple logical truth amounts to an epistemological analyticity.

Williamson tries to preempt this line of thought in two different ways. On the one hand, he emphasizes that 'every' in Peter's mouth must mean the same as it does in our mouths; after all, we all speak English. On a strict Lewisian individuation of natural languages [Lewis 1975], this does indeed follow. But Williamson employs far more lenient criteria for speaking the same natural language, viz., fluency of communication [Williamson 2006, 11f] and nondeviant first acquisition [Williamson 2006, 13], as he needs to do to bestow prima facie plausibility on his idea that Peter speaks the same language as we do. And on these criteria, sameness of natural language does not guarantee sameness of meaning.

This fits well with the natural languages we know. Consider e.g., the term 'hat'. According to the OED, there are two uses of this word. On the former, a hat is almost any covering for the head. On the latter, a hat is a specific kind of headgear that typically has "a more or less horizontal brim all round the hemispherical, conical, or cylindrical part which covers the head". Thus there might well be a community of English speakers whose members exclusively use 'hat' in the former sense, and one whose members exclusively use 'hat' in the latter sense. The overlap in the senses would allow ordinary communication to proceed by and large smoothly. Still, the communities would use 'hat' in different senses. Meaning can thus cut finer than shared natural language. ${ }^{11}$ Hence, the

11. Discussing the idea that concepts are much more finely individuated than linguistic meanings, Williamson argues that it creates methodological issues such as:

to which concept does the phrase 'the concept square' refer to if the word 'square', with its usual meaning in English, is associated with different 
fact that we all speak English is consistent with the fact that 'every' in Peter's mouth means something different from what it means in our mouths.

On the other hand, Williamson thinks that a homophonic rendering of Peter's: "Every vixen is a vixen" is more faithful to his intentions than any nonhomophonic reading. After all, Peter's logical theory attempts to capture our shared meaning of 'every'. From this Williamson concludes that Peter associates the sentence: "Every vixen is a vixen" with "the same thought as we do in any relevant sense of 'thought"' [Williamson 2006, 25]. But that inference is flawed. In most contexts, we report homophonically because the differences in truthconditions do not matter. And in contexts where these differences do matter, we report homophonically because we lack a word expressing Peter's sense of 'every'. ${ }^{12}$ But when it matters, we flag the differences: "Peter denies that every vixen is a vixen. You see, the way he uses 'every' is such that such a claim is true only if there are some of these things, and Peter believes that there are no vixens." In writing we can easily devise a new term, and we would not hesitate to distinguish our 'every,' from Peter's 'every2'. There is nothing paternalistic about this. We have diagnosed a simple difference in use and meaning, and highlight it.

Please note that a difference is all we need. We hold that "Every vixen is a vixen" is a conceptual truth in our community because we think it obvious that we use 'every' in the sense of 'every 1 '. Peter's challenge might prompt us to reflect about the way we do and would use 'every' in order to determine whether the seemingly innocuous "Every vixen is a vixen" is indeed analytic in our community. But the fact that Peter's challenge prompts us to re-assess our judgment as to how we employ the term across possible situations does not imply that "Every vixen is a vixen" is not a conceptual truth in our community. Even less does it follow that since such a challenge is possible in any single case, there are no epistemic analyticities. This merely implies that our judgements about which statements are conceptual truths are generally defeasible.

Yet that is granted anyway. There might always be a queer possible situation we have not thought of-as I have stressed above, our armchair-based accounts of the notions guiding our considered application are typically conjectural, always defeasible and very often provisional. But Peter does not draw our attention to a possible situation contemplation on which is expected to convince us that we, at least sometimes, employ "Every $F$ is $G$ " such that it entails "There are $F s$ ". He maintains that we are wrong about the semantics of 'every' in our mouths although we know perfectly well how we do and would use that term. Please recall that Williamson stipulates that Peter's refusal to accept "Every

concepts in the minds of different speakers of English at one time (...)?

[Williamson 2003, 271f]

But the claim is that meaning can cut finer than shared natural language, not that it must cut finer.

12. See [Segal 2000, 76-83] for an argument along these lines. 
vixen is a vixen" is stable under reflection, exposure to further arguments, and the like. By parity of reasoning, we can assume that our refusal to give in to Peter's account is likewise stable such that learning more about how we do and would use 'every' won't change our verdict either.

I conclude that Williamson hasn't established that there are no epistemic analyticities. A fortiori, he hasn't shown that there is no conceptual knowledge. In the light of the positive case offered in the last section, we can rest assured that we do in fact have conceptual knowledge. The first premise of the simple argument still stands tall, or so I maintain.

\section{From conceptual truths to metaphysical necessities, or the argument from strong possibilities}

Turning to the second premise of the simple argument, I need to show that

(2) Any item of conceptual knowledge we so possess either ipso facto is knowledge of a metaphysical necessity. Or the conceptual knowledge we are concerned with is such that we can reliably determine that it does not lead to metaphysically modal knowledge.

Here is a quick argument for this premise. We do have knowledge of conceptual truths, or so the first premise of the simple argument assures us. Given the distinctions made in $\S 3$ above, we know that a conceptual truth amounts to a statement that holds true across all counter-actual or A-worlds (in symbols: $\square_{A} S$ ). But any such conceptually necessary statement is ipso facto metaphysically necessary in that it holds true across all counterfactual or C-worlds as well (in symbols: $\square_{C} S$ ). That is to say, the following principle I dub the 'NN-Rule' holds true:

(NN) If statement $S$ is conceptually necessary, $S$ is metaphysically necessary as well (in symbols: $\square_{A} S \rightarrow \square_{C} S$ )

On the NN-rule, then, conceptual necessities are directly convertible into metaphysical necessities. Hence, premise (2) holds true in virtue of its first disjunct holding true: Any item of conceptual knowledge we possess ipso facto is knowledge of a metaphysical necessity.

The quick argument clearly is too quick. It presumes that there are no defeaters to the NN-rule. But Kripke [Kripke 1980, 53-56] has shown that we find statements that defeat it. Consider: "The standard meter is one meter long at $t_{0}$." Although this statement expresses a conceptual truth, it is metaphysically contingent rather than metaphysically necessary. It thus defeats the NN-rule. But if there are defeaters to the NN-rule, we cannot rely on it to convert some 
conceptual truth $S$ we have arrived at by conceptual reflection into a metaphysical necessity. For how can we make sure that $S$ does belong to the statements the NN-rule holds true for?

So the quick argument won't do. But something very much like it will do, for all exceptions to the NN-rule are identifiable in advance, or so I will argue. That is to say, the NN-rule fails only for statements for which we can know, by armchair semantic consideration, that it fails for them. All defeaters of the NNrule thus are harmless. If this is true, then we can decide, for any conceptual necessity we find, whether it yields a metaphysical necessity, or whether it is a defeater to the NN-rule. Conceptual reflection thus puts us in a position to safely derive metaphysical necessities from insights gained by conceptual analysis.

Please note that distinguishing between counter-actual or A-worlds and counterfactual or C-worlds allows us to distinguish two kinds of truth-conditions, and hence two kinds of contents encapsulating those. On the one hand, there are counter-actual truth-conditions-A-contents, for short. These capture the conceptual dimension in that, as rehearsed above, a statement $S$ is conceptually necessary iff it holds true in all A-worlds. On the other hand, there are the more familiar counterfactual truth-conditions-the $C$-contents, for short. These capture the metaphysical dimension in that, as already explained, a statement $S$ is metaphysically necessary iff it holds true in all counterfactual or C-worlds. Any defeater of the NN-rule must hence be such that its A-contents are necessary whereas its C-contents aren't. So let us consider what could make a statement's counterfactual and counter-actual truth-conditions differ. Two answers to this are widely discussed.

The first idea is this: A statement's counterfactual and counter-actual truth-conditions may differ if the statement contains actuality-dependent terms. Actuality-dependent expressions such as 'here', 'water' or 'one meter' designate rigidly whatever actual extension their A-contents carve out. This might well make that their C-contents deviate from their A-contents. A statement's C-content may hence differ from its A-content because it contains actualitydependent terms. ${ }^{13}$ This yields clear defeaters for the NN-rule. Actualitydependence brings about a posteriori necessities such as "Water is $\mathrm{H}_{2} \mathrm{O}$ " with 'water' rigidly designating the substance 'water' actually applies to. Actuality dependence also brings about a priori contingencies such as "The standard meter is one meter long at $t_{0}$." The latter combine a necessary A-content with a contingent C-content and hence defeats (NN). Yet these defeaters are harmless. Since we can diagnose actuality-dependence by armchair semantic considerations, statements whose C- and A-contents deviate because they comprise actuality-dependent terms are recognizable from the armchair. Given that we

13. May, but need not. For many actuality-dependent sentences it holds true that if they are conceptually necessary, they are metaphysically necessary. Consider e.g., "Water is the actual watery stuff of our acquaintance" or "One meter is the actual length of the standard meter at $t_{0} . "$ 
reflect on that matter, and given that we are alert to the possibility that apriority and metaphysical necessity may come apart, we simply won't mistake $a$ priori contingencies such as "The standard meter is one meter long at $t_{0}$ " for metaphysical necessities.

Neo-descriptivists hold that actuality-dependence is the only reason for a statement's C- and A-contents to differ, and thus the only source of a posteriori necessities. Quite a few philosophers reject this claim. This brings us to the second idea as to how a statement's counterfactual and counter-actual truthconditions may come apart. Advocates of so-called strong necessities hold that "God exists", " $e=m c^{2}$ ", or the key materialist claim $\square(P H Y S \rightarrow P H E N){ }^{14}$ state a posteriori necessities, although they do not contain actuality-dependent terms and we judge them to be false in some A-world [Chalmers 2002, 189192], [Kallestrup 2006]. For any such statement $S$, it holds true that $\square_{C} S \& \neg \square_{A}$ $S$. Hence, any strong necessity is putative example of a non-actuality-dependent statement whose A- and C-contents nonetheless differ.

Chalmers [Chalmers 2010], [Chalmers 2002, 189-194] argues that there are no strong necessities. He points out that we have no reason to think that the examples given are metaphysically necessary in the first place, that strong necessities presuppose inexplicable brute modal facts, and that their existence would require the space of A-worlds to outrun the space of C-worlds. This fact would violate modal monism on which A- and C-world are the same worlds viewed under different perspectives. But modal monism provides a prima facie highly plausible account of modal space, and it is less opulent than any picture assuming A- and C-worlds to be different entities. So Chalmers concludes that we have good reason to think that there are no strong necessities.

Still, many philosophers maintain that things are different when it comes to the phenomenal, and they accept that $\square(P H Y S \rightarrow$ PHEN) is a strong necessity. They argue that we have good reasons to uphold physicalism and reject mind-body dualism, and they provide a theory of phenomenal concepts to explain how strong necessities involving those concepts come about [Tye 2003]. I am rather wary of this line of argument, ${ }^{15}$ and I consider strong necessities to be rather dubious. But let us for the moment acknowledge them. Let us agree that there are as many strong necessities as you like. How does this affect the case to be made here in support of premise (2) of our simple argument?

Acknowledging strong necessities does not affect this case at all. For strong necessities do not affect the NN-rule. Actuality-dependence yields defeaters to the NN-rule that are harmless. Strong necessities are far from harmless. We won't learn that some statement expresses a strong necessity by armchair semantic considerations. But strong necessities do not defeat (NN). Put simply, if there are strong necessities, there are more A-worlds than C-worlds: Since

14. Here 'PHYS' abbreviates a statement that reports all actual (micro-)physical facts and 'PHEN' abbreviates a statement that reports all actual phenomenal facts.

15. See [Horgan \& Tienson 2001] for a general argument against these views. 
a strong necessity $S$ is true in all C-worlds but false in some A-worlds, these A-worlds cannot be C-worlds. But if there are more A- than C-worlds, arguing from the truth of "God does not exist" or "PHYS \& $\neg$ PHEN" in some A-world to their truth in some C-world becomes problematic. Strong necessities thus would defeat the following principle I dub the 'PP-Rule':

(PP) If statement $S$ is conceptually possible, $S$ is metaphysically possible as well (in symbols: $\diamond_{A} S \rightarrow \nabla_{C} S$ ).

This would be significant enough. But it would not affect the NN-rule. The NN-rule entails that $\nabla_{C} S \rightarrow \diamond_{A} S$ holds true. This rule cannot be invalidated by statements falsifying the converse $\nabla_{A} S \rightarrow \diamond_{C} S$.

So we find that neither of the reasons the current debate contemplates for a statement's C-content to deviate from its A-content yields harmful defeaters for the NN-rule. This was to be expected. Any harmful defeater to (NN) would have to be a non-actuality dependent statement stating a metaphysical contingency that we nevertheless judge to be true in all A-worlds. In other words, any harmful defeater to (NN) would have to be a strong possibility. Only for strong possibilities $S$ does $\square_{A} S \& \neg \square_{C} S$ hold true in spite of the absence of any actuality-dependent terms, which is what we would need for defeater of (NN) that we cannot diagnose by armchair semantic reflection.

To my knowledge, no one has ever defended strong possibilities, or produced a single example. What is more, anyone who recognizes metaphysical necessity has good reasons to doubt that there are any strong possibilities.

First of all, suppose someone takes "Some grandmothers aren't female" to state a strong possibility. She has to hold that (i) "All grandmothers are female" is conceptually necessary, that (ii) there nevertheless are metaphysically possible worlds with non-female grandmothers, and that (iii) "All grandmothers are female" does not function like "Water is watery", since neither 'grandmother' nor 'female' is actuality-dependent. But taken together, (ii) and (iii) seem to contradict (i). Our speaker seems to hold that there is some possible situation correctly describable as containing non-female grandmothers and to hold that there is no possible situation correctly describable as containing non-female grandmothers whilst agreeing that 'female grandmother' applies to precisely the same objects in both possible situations.

Secondly, to hold that there is a statement $S$ such that $\square_{A} S \& \neg \square_{C} S$ is to agree that there is a statement $S^{\prime}$ such that $\neg \nabla_{A} S^{\prime} \& \diamond_{C} S^{\prime}$. To accept strong possibilities is thus to accept that some conceptual impossibilities are metaphysically possible. But everyone treats conceptual impossibility as sufficient for metaphysical impossibility. No one who grants that: "There are round squares" or "There are married bachelors" are conceptually impossible (and non-actuality dependent) thinks that we still need to check whether they are metaphysically possible. That is exactly right. If there are Moorean facts about modality, that there cannot be a metaphysically possible world in which a conceptual impossibility holds true is clearly one of them. 
Finally, if there are strong possibilities, there are more C-worlds than Aworlds: Since a strong possibility $S$ is false in some C-worlds but true in all A-worlds, these C-worlds cannot be A-worlds. So if there are strong possibilities, there are metaphysically possible worlds that are conceptually impossible. An advocate of strong possibilities thus had to avow that metaphysical necessity outruns conceptual necessity. This would mean to embrace modal dualism. It would also run counter to everything we thought we knew about how conceptual and metaphysical modality are related. Anyone who acknowledges metaphysical modality at all will agree that although modal space may have some unexpected features, it cannot deviate that much from how we think it is.

I conclude that there are no strong possibilities. Consequently, there are no harmful defeaters to the NN-rule. Hence, premise (2) of the simple argument holds good. By consequence, the conceptual knowledge we possess reliably yields knowledge of metaphysical necessities.

\section{Wrapping up, or modal knowledge and metaphysical ambition}

I have argued that there are conceptual truths we know since we know what our terms semantically apply to. Yet any such conceptually true statement $S$ we know either ipso facto provides us with knowledge of a metaphysical necessity. This holds true if $S$ is conceptually necessary and does not comprise any actuality-dependent term. Or $S$ comprises at least one actuality-dependent expression, making its extension across counterfactual worlds dependent on (as a rule) contingent actual fact. Then our knowledge of $S$ does not provide us with knowledge of a metaphysical necessity. But since we can uncover actualitydependence by armchair semantic reflection, we are in a position to know that $S$ does not ipso facto amount to a metaphysical necessity. Hence, our ordinary knowledge of conceptual truths, knowledge we possess since we know what (many of) our terms semantically apply to, is a reliable epistemic source of, and hence a reliable route to, knowledge of metaphysical necessities.

This argument relies neither on an extravagant theory of concept possession, nor on fancy ideas about matters modal. The claim that we do possess conceptual knowledge rests on what appears to be a broad consensus in semantics, viz. that we often do know what our terms semantically apply to, since we know how we do and would apply them. And as for modal part, no one granting that: "You do not know that $p$ if $p$ is false", "Neighbours have neighbours", "Uncles are relatives" or "Hats are coverings of the head" express conceptual necessities goes on to wonder whether these statements may still be false at some metaphysically possible world or other-unless, that is, she suspects a somewhat hidden actuality-dependence. There thus de facto is something like a consensus that conceptual knowledge allows us to uncover metaphysical necessities. 
Since there is no reason to think that ways to acquire modal knowledge are mutually exclusive, you still might want to explore alternative epistemic routes to modal truth. You might try to gather modal knowledge from conceivability [Yablo 1993], [Chalmers 2002], from our empirically informed ability to pass counterfactual judgment [Williamson 2007, chap. 5], or from inferences to best explanation [Biggs 2011]. But is there any need to do so, now that we know that we can rely on our ordinary conceptual knowledge? That depends on how grand your metaphysical ambitions are. If you are content with metaphysically modal insights such as the ones concerning circles, knowledge, neighbours, uncles and hats paraded above together with a posteriori necessities such as "Water is $\mathrm{H}_{2} \mathrm{O}$ ' or "Hesperus = Phosphorus" derived from conceptual truths in tandem with empirical discoveries, you won't feel much pressure to do so. Yet if you are a staunch believer in more ambitious metaphysical necessities such as, say, the necessity of origin or substance, or if you wish to uncover metaphysical possibilities (that aren't metaphysically necessary), I fear you will want to keep looking. ${ }^{16}$

\section{Bibliography}

AYER, ALFRED

1946 Language, Truth, and Logic, London: Penguin Books.

BALCERAK JACKSON, BRENDAN

2009 Understanding and semantic structure: A reply to Williamson, Proceedings of the Aristotelian Society, 109(1), 338-343.

BEALER, GEORGE

1998 A theory of concepts and concept possession, Philosophical Issues, 9, 261-301.

2000 A theory of the A Priori, Pacific Philosophical Quarterly, 81(1), 1-30.

BIGGS, STEPHEN

2011 Abduction and modality, Philosophy and Phenomenological Research, 83, 283-326.

BOGHOSSIAN, PAUL

1997 Analyticity, in A Companion to the Philosophy of Language, edited by HALE, B. \& WRIGHT, C., Oxford: Blackwell, 331-368.

2003 Epistemic analyticity: A defence, Grazer Philosophische Studien, 66, 15-35.

16. I am indebted to two unknown referees for Philosophia Scientiæ, as well as to Peter Schulte. Their criticism has helped me to substantially improve on the initial draft of this article. I would also like to thank the participants at the 2010 Nancy conference on "Modality-Semantics and Epistemology" where I first presented the material for many valuable comments. 
CAMERon, Ross P.

2009 What's metaphysical about metaphysical necessity?, Philosophy and Phenomenological Research, 79(1), 1-16.

2010 The grounds of necessity, Philosophy Compass, 5/4, 348-358.

Chalmers, DAVID

2002 Does conceivability entail possibility?, in Conceivability and Possibility, edited by Gendler, T. S. \& HaWthorne, J., Oxford: Clarendon Press, 145-200.

2004 Epistemic two-dimensional semantics, Philosophical Studies, 118(12), 153-226.

2010 The two-dimensional argument against materialism, in The Character of Consciousness, Oxford, New York: Oxford University Press, 141-191.

GRAYLING, ANTHONY C.

1997 An Introduction to Philosophical Logic, Oxford: Blackwell.

Hale, Bob \& Hoffmann, Aviv (EDs.)

2010 Modality. Metaphysics, Logic, and Epistemolgy, Oxford: Oxford University Press.

HANFLING, OSWALD

2000 Philosophy and Ordinary Language. The Bent and Genius of our Tongue, London: Routledge.

HoRgan, TERENCE \& TIENSON, JOHN

2001 Deconstructing new wave materialism, in Physicalism and Its Discontents, edited by Gillett, C. \& Loewer, B., Cambridge: Cambridge University Press, 307-318.

JACKSON, FRANK

1998 From Metaphysics to Ethics. A Defense of Conceptual Analysis, Oxford: Oxford University Press.

2004 Why we need A-intensions, Philosophical Studies, 118(1-2), 257277.

2007a Reference and description from the descriptivists' corner, Philosophical Books, 48(1), 17-26.

2007b On not forgetting the epistemology of names, Grazer Philosophische Studien, 74, 239-250.

2010 Conceptual analysis for representationalists, Grazer Philosophische Studien, 81, 173-188. 
KALLESTRUP, JESPER

2006 Physicalism, conceivability, and strong necessities, Synthese, 15(3), 273-295.

KNOBE, JoshuA \& Nichols, SHAUN

2008 Experimental Philosophy, Oxford: Oxford University Press.

KRIPKE, SAUL

1980 Naming and Necessity, Oxford: Blackwell.

LEWIS, DAVID

1972 Psychological and theoretical identifications, in Papers in Metaphysics and Epistemology, Cambridge: Cambridge University Press, 248-261, 1999.

1975 Language and languages, in Philosophical Papers I, Oxford: Oxford University Press, 163-188, 1983.

1986 On the Plurality of Worlds, Oxford: Blackwell.

1994 David Lewis-Reduction of mind, in Papers in Metaphysics and Epistemology, Cambridge: Cambridge University Press, 291-324.

1997 Naming the colours, in Papers in Metaphysics and Epistemology, Cambridge: Cambridge University Press, 332-358.

MCLEOD, STEPHEN

2005 Recent work on modal epistemology, Philosophical Books, 46(3), 235-245.

NimTZ, CHRISTIAN

2009 Conceptual truth defended, in The A Priori and Its Role in Philosophy, edited by Kompa, N., NimTz, C., \& SuHM, C., Paderborn: mentis, 137155.

2010 Philosophical thought experiments as exercises in conceptual analysis, Grazer Philosophische Studien, 81, 191-216.

\section{PEACOCKe, Christopher}

1999 Being Known, Oxford: Clarendon Press.

2002 Précis of being known, Philosophy and Phenomenological Research, 64(3), 636-640.

PUTNAM, HiLARY

1963 Mind, Language, and Reality. Philosophical Papers, Cambridge: Cambridge University Press, vol. 2, chap. The Analytic and the Synthetic, 33-69, 1975.

1975 The meaning of 'meaning', in Mind, Language, and Reality. Philosophical Papers, Cambridge: Cambridge University Press, vol. 2, 215-271. 
ROCA-ROYES, SÒNIA

2011 Modal knowledge and counterfactual knowledge, Logique et Analyse, 54(216), 537-552.

ROSEN, GIDEON

2002 Peacocke on modality, Philosophy and Phenomenological Research, 64(3), 641-648.

SEgAL, GABRIEL

2000 A Slim Book of Narrow Content, Cambridge (Mass.): MIT Press.

SOAMES, SCOTT

2002 Beyond Rigidity. The Unfinished Semantic Agenda of 'Naming and Necessity', Oxford: Oxford University Press.

SOSA, DAVID

1998 Getting clear on the concept, Philosophical Issues, 9, 317-322.

SPICER, FINN

2010 Kripke and the neo-descriptivist, Grazer Philosophische Studien, 81, 215-233.

TYE, MiCHAEL

2003 A theory of phenomenal concepts, Royal Institute of Philosophy Supplement, 53, 91-105.

VAIDYA, ANAND J.

2007 The epistemology of modality, The Stanford Encyclopedia of Philosophy, edited by Zalta, E. .N., Winter 2011 edition, http://plato.stanford.edu.

WILLIAMSON, TIMOTHY

2002 Peacocke's theory of modality, Philosophy and Phenomenological Research, 64(3), 649-654.

2003 Understanding and inference, Aristotelian Society Supplement, 77(1), 249-293.

2006 Conceptual truths, Aristotelian Society Supplement, 80(1), 1-41.

2007 The Philosophy of Philosophy, Oxford: Blackwell.

YABLO, STEPHEN

1993 Is conceivability a guide to possibility?, Philosophy and Phenomenological Research, 53(1), 1-41. 